Relations industrielles

Industrial Relations

\title{
Great Myths of Economics, by Dan Paarlberg, The New American Library Inc., New York, 1968, 206 pp.
}

\section{Jean Boivin}

Volume 23, numéro 2, 1968

URI : https://id.erudit.org/iderudit/027908ar

DOI : https://doi.org/10.7202/027908ar

Aller au sommaire du numéro

Éditeur(s)

Département des relations industrielles de l'Université Laval

ISSN

0034-379X (imprimé)

1703-8138 (numérique)

Découvrir la revue

Citer ce compte rendu

Boivin, J. (1968). Compte rendu de [Great Myths of Economics, by Dan

Paarlberg, The New American Library Inc., New York, 1968, 206 pp.] Relations

industrielles / Industrial Relations, 23(2), 370-370.

https://doi.org/10.7202/027908ar

Tous droits réservés @ C Département des relations industrielles de l'Université Laval, 1968
Ce document est protégé par la loi sur le droit d'auteur. L’utilisation des services d'Érudit (y compris la reproduction) est assujettie à sa politique d'utilisation que vous pouvez consulter en ligne.

https://apropos.erudit.org/fr/usagers/politique-dutilisation/ 
make them mosters and not servonts of science.

It is definitely a book to read even if we ore bent to poss over a few chapters much too concerned by historical and technical details.

\section{L.-René PARENTEAU}

Rotation des stocks et marge bénéficiaire ò l'américaine, par John P. D'Anna, Entreprise Moderne d'Edition, Paris, 1968, 90 pp.

Le livre de John P. D'Anno de la General Ford publié en 1966 sous le titre américain - Inventory and Profit» par The American Manogement Association Inc. est d'un accès focile, sans tomber dans la simplification abusive qu'entraîne trop souvent le souci de vulgariser. II constitue par conséquent une excellente introduction à cet aspect particulier du marketing dont il traite. La compréhension est de plus largement favorisée par l'insertion en annexe d'une série de questions qui s'adressent au lecteur.

Les idées développées dans cet ouvrage sont suffisamment connues en Amérique du Nord pour que nous puissions foire l'économie d'un long commentaire.

L'édition française porte en sous titre - à l'oméricaine ». Y aurait-il dans ce domaine des différences fondamentales entre les Etats-Unis et l'Europe et plus particulièrement la France? Les succès remportés par les firmes américaines nouvellement implantées dans les six pays de la Communouté économique européenne tendent à démontrer que les principes du marketing américain sont au prix de quelques ajustements mineurs parfaitement compatibles avec les conditions particulières existant outre Atlantique.

\section{Bernard SOLASSE}

Great Myths of Economics, by Don Poarlberg, The New American Library Inc., New York, 1968, $206 \mathrm{pp}$.

$\mathrm{Ce}$ livre essaie de dissiper les grands mythes économiques qui ont été acceptés comme des évangiles par les profanes. Pour être bien compris de tous, l'auteur emploie un langage simple et concis

Avec objectivité le professeur Poarlberg tente, dons une première partie, de détruire les fausses croyances d'un public mal informé au sujet des politiques monétaires, du contrôle gouvernemental, des biens de con- sommation privés et socioux, de l'exploitation, etc. Puis, dans une seconde partie, i expose les principaux concepts de la politique économique moderne tels: le marché de concurrence, le marché de monopole, la consommation, la production, les salaires, la monnaie, le crédit et les prix ainsi que le développement économique. Finalement, il termine avec un appendice dans lequel if mentionne les principoux autres travaux qui ont écrits sur les problèmes économiques récents.

Tout au long du volume, I'auteur situe lo théorie et lo pratique économiques ò portir des dogmes des économistes classiques et marxistes jusqu'ò la révolution keynesienne.

Grâce ò so connaissance du sujet et son exceptionnel talent d'écrivain lucide, le professeur Poarlberg permet au lecteur de comprendre le fonctionnement pratique du monde économique compliqué dans lequel nous vivons.

L'outeur indique clairement au déport so ferme conviction dans la supériorité de l'économie de marché telle que nous la connaissons en Occident. Par contre, durant tout le volume, il indique les différentes alternatives face à des problèmes économiques bien concrets.

En critiquant les solutions des premiers économistes de la civilisation industrielle, l'auteur ne se fera sûrement pas d'amis parmi les gens d'extrême droite ni d'extrême gauche. Ainsi, s'il reconnait les désavantages d'une économie libérale laissée pleinement à elle seule, il condamne aussi bien les contrôles rigides de l'Etat.

Par conséquent, le livre Great Myths of Economics illumine clairement les principaux principes qui guident le comportement de I'homme selon qu'il sait s'en servir adéquatement ou qu'il en abuse.

\section{Jean BOIVIN}

Lo stratégie des négociations collectives, par Denis Carrier, Les Presses Universitaires de France: [Travaux et recherches de la Faculté de Droit et des Sciences Economiques de Paris, série «Sciences Economiques ע, no 5 , préfacé por Henri Bartoli, 160 pages, 1967 - 4]

L'auteur se propose de rechercher une méthode et une opproche pour systématiser I'analyse des rapports collectifs du travail. 